\title{
TERAPIA FOTODINÂMICA: PRINCÍPIOS, POTENCIAL DE APLICAÇÃo E PERSPECTIVAS
}

\author{
Antonio Eduardo da Hora Machado* \\ Instituto de Química - Universidade Federal de Uberlândia - CP 593 - 38400-089 - Uberlândia - MG
}

Recebido em 19/10/98; aceito em 8/7/99

\begin{abstract}
Photodynamic Therapy: Principles, Potential of Application and Perspectives. Photodynamic Therapy (PDT) has been designated as a promising new modality in the treatment of cancer and other diseases since the early 1980s. It has been used with success for the treatment of a variety of tumours, and attempts are being made to extend this treatment modality to other clinical conditions (as example, the inactivation of viruses in blood and blood components). This can be partly attributed to the very attractive basic concept of PDT: the combination of a photosensitizing drug and light, which are relatively harmless by themselves but combined (in the presence of oxygen) ultimately cause more or less selective tumour destruction.
\end{abstract}

Keywords: photosensitization; oxygen active species; singlet oxygen; cancer therapy.

\section{INTRODUÇÃO}

Colorantes (corantes e pigmentos) são caracterizados pela sua habilidade de absorver luz visível. Ao menos, cerca de 10.000 desses compostos químicos coloridos tem sido produzidos em escala industrial ${ }^{1}$. Em função do fato de absorverem luz com elevada eficiência, em alguma região do espectro visível, alguns desses compostos são capazes de induzir ou participar de reações fotoquímicas.

Desde o início do século, tem-se discutido o emprego de colorantes como drogas. Certos corantes tem sido empregados como agentes terapêuticos, como é o caso do azul de metileno, que possui ação bacteriostática, violeta de genciana (cristal violeta), dentre muitos outros. Raab ${ }^{2}$, em 1900, observou a morte de microorganismos quando expostos à luz solar e ao ar, na presença de certos corantes. O que Raab reportou é o princípio de uma nova modalidade clínica para o tratamento do câncer e outras moléstias, conhecida como Terapia Fotodinâmica (TFD). A Terapia Fotodinâmica parte do princípio de que a interação de luz de comprimento de onda adequado com um composto nãotóxico (fotosensitizador) e oxigênio, resulta em espécies reativas capazes de induzir a inviabilização de células, que causou a morte dos microorganismos observada por $\mathrm{Raab}^{2}$. Isso é resultado da reação envolvida, que decorre primáriamente da excitação eletrônica do corante pela luz, seguida de dois mecanismos principais de reação, a partir do seu estado excitado ${ }^{3,8,71}$ :

- Transferência de elétron (mecanismo tipo I) entre o fotosensitizador no estado triplete excitado e componentes do sistema, gerando íons-radicais que tendem a reagir com o oxigênio no estado fundamental, resultando em produtos oxidados:

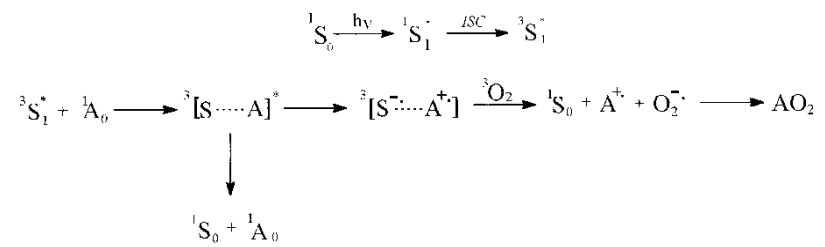

Esquema 1. Esquema típico para as reações do Tipo I (Transferência de Elétron): $S$ representa o sensitizador, e A a molécula que será oxidada.

*e-mail: aeduardo@ufu.br
Em geral, processos de transferência de elétron tendem a ser muito rápidos porque a sobreposição dos orbitais envolvidos, durante a formação do complexo excitado, é máxima ${ }^{11}$. A natureza exata do processo (se serão formados $S^{+}$e $A^{-}$ou $S^{-}$ $e B^{+.}$) dependerá das propriedades redóxi de ${ }^{3} \mathrm{~S}^{*}$ e de ${ }^{1} \mathrm{~A}^{11,12}$.

- Transferência de energia (mecanismo tipo II) do fotosensitizador no estado triplete, com a geração de oxigênio singlete, um agente altamente citotóxico:

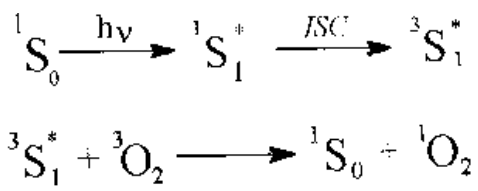

${ }^{1} \mathrm{O}_{2}+{ }^{{ }^{1}} \mathrm{~A}_{0} \longrightarrow$ REACÕES POSTERIORES

Esquema 2. Esquema típico para as reações do Tipo II (Transferência de Energia).

Oxigênio singlete é como são conhecidos os três estados eletronicamente excitados imediatamente superiores ao oxigênio molecular no estado fundamental $\left({ }^{3} \Sigma\right)^{3,12}$. Segundo a Teoria do Orbital Molecular, a configuração eletrônica do oxigênio no estado fundamental possui dois elétrons desemparelhados nos orbitais moleculares degenerados $\pi_{x}^{*} e \pi_{y}^{*}$. Esses elétrons tendem a possuir o mesmo spin de forma a produzir multiplicidade máxima e assim um estado de mais baixa energia. Essa é a razão pela qual o estado fundamental do oxigênio molecular é um triplete. A Tabela 1 apresenta as formas de ocupação nesses orbitais moleculares antiligantes, para o oxigênio no estado fundamental, assim como para os estados excitados imediatamente superiores,

Tabela 1. Ocupação dos orbitais moleculares antiligantes para os estados eletrônicos do $\mathrm{O}_{2}$.

\begin{tabular}{ccc}
\hline Estado & $\begin{array}{c}\text { Orbital molecular } \\
\text { antiligante }\end{array}$ & Energia $^{*}, \mathrm{kJmol}^{-1}$ \\
\hline${ }^{3} \sum \mathrm{g}$ & {$[\uparrow] \pi^{*}{ }_{\mathrm{x}}[\uparrow] \pi^{*}{ }_{\mathrm{y}}$} & 0 \\
${ }^{1} \Delta \mathrm{x}$ & {$[\uparrow \downarrow] \pi^{*}{ }_{\mathrm{x}}[\uparrow] \pi^{*}$} & 92,4 \\
${ }^{1} \Delta \mathrm{y}$ & {$\left[[] \pi_{\mathrm{y}}^{*}[\uparrow \downarrow] \pi^{*}\right.$} & 92,4 \\
${ }^{1} \sum \mathrm{g}$ & {$[\uparrow] \pi^{*}{ }_{\mathrm{x}}[\downarrow] \pi^{*}$} & 159,6 \\
\hline
\end{tabular}

* relativa ao estado fundamental 
Desses estados, os que possuem energia intermediária $\left({ }^{1} \Delta_{\mathrm{X}}\right.$ e ${ }^{1} \Delta_{\mathrm{y}} ; 92,4 \mathrm{~kJ} \mathrm{~mol}^{-1}$ ) são os responsáveis pela reatividade química do oxigênio singlete. A simetria dessas moléculas, diferente da do estado fundamental, lhes garante um considerável tempo de vida quando comparado com a forma de mais alta energia $\left({ }^{1} \Sigma ; 159,6 \mathrm{~kJ} \mathrm{~mol}^{-1}\right)$, que possui a mesma simetria do estado fundamental. Os estados ${ }^{1} \Delta_{\mathrm{x}}$ e ${ }^{1} \Delta_{\mathrm{y}}$ são degenerados e possuem uma distribuição eletrônica onde os elétrons que ocupam um dos orbitais antiligantes $\pi^{*}$ se encontram em um dos planos mutuamente perpendiculares,

Por serem degenerados, os estados ${ }^{1} \Delta_{\mathrm{x}} \mathrm{e}{ }^{1} \Delta_{\mathrm{y}}$ são, por conveniência, representados como sendo o estado ${ }^{1} \Delta_{\mathrm{g}}$. O orbital molecular vazio no estado ${ }^{1} \Delta_{\mathrm{g}}$ (v. Fig. 1) garante ao oxigênio singlete essa espécie caráter eletrofílico, o que favorece sua participação mais efetiva em reações químicas, principalmente no caso em que os substratos possuem sítios ricos em elétrons.

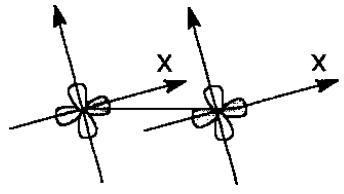

$\left({ }_{\Delta x}\right)$

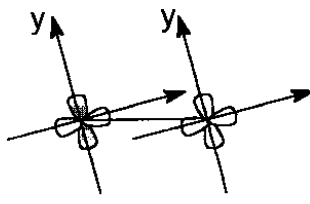

$\left({ }^{1} \Delta y\right)$
Figura 1. Representação dos orbitais moleculares $\pi_{x}{ }^{*} e \pi_{y}{ }^{*}$ relativos às formas ${ }^{1} \Delta_{x} e^{I} \Delta_{y}$ do oxigênio singlete: os lóbulos sombreados representam o orbital molecular antiliante que possui o par de életrons.

O tempo de vida do oxigênio singlete em solução é profundamente influenciado pela natureza do solvente ${ }^{3}$ : em água, por exemplo, é de cerca de $4,0 \mu \mathrm{s}^{3 \mathrm{~b}}$; Já em água deuterada, $\tau$ situase em torno de $70 \mu \mathrm{s}$. Em geral, em solventes que não possuem ligações $\mathrm{C}-\mathrm{H}$ e grupos hidroxila na sua estrutura, o tempo de vida do oxigênio singlete tende a valores mais elevados. Por exemplo, para o tetracloreto de carbono, o tempo de vida do oxigênio singlete é de cerca de $30 \mathrm{~ms}$, e em clorofórmio, $250 \mu \mathrm{s}^{3 \mathrm{~b}}$. A razão para certos grupos funcionais ou átomos suprimirem mais ou menos eficientemente o oxigênio singlete, encontra-se na possibilidade de transferência de energia eletrônica do oxigênio singlete para certos estados vibracionais associados às espécies supressoras ${ }^{3 \mathrm{c}}$.

Em sistemas biológicos, o oxigênio singlete apresenta tempos de vida extremamente baixos, inferiores a $0,04 \mu \mathrm{s}^{71,94}$. Em função disso, seu raio de ação é extremamente reduzido $(<0,02 \mu \mathrm{m})^{8,71,94}$.

Foi Gollnick quem primeiramente associou a atividade tumoricida da TFD à ação de radicais livres ${ }^{10}$. Espécies radicalares, tanto ânions-radicais superóxido, cátions ou ânionsradicais baseados no sensitizador, assim como inúmeras outras espécies ativas de oxigênio, são formadas tanto nos processos primários (ânion-radicais superóxido e cátion-radicais baseados no sensitizador), mediante reação de treansferência de elétron, como na propagação da cadeia de reações (ânion-radicais superóxido e outras espécies ativas de oxigênio). Reações envolvendo radicais livres tem sido confirmadas tanto por experimentos de fotólise relâmpago (flash photolysis) em sistemasmodelo, como também empregando-se técnicas de RPE (EPR spin trapping) em sistemas biológicos ${ }^{13}$

A ação do oxigênio singlete $\left({ }^{1} \mathrm{O}_{2}{ }^{1} \Delta_{\mathrm{g}}\right)$ na morte ou inviabilização de células tumorais tem sido evidenciada de diversas maneiras. Korytowski e colaboradores ${ }^{14,15}$ isolaram os compostos $3 \beta$-hidróxi-5 $\alpha$-colest-6-eno-5-hidroperóxido (I), $3 \beta$ hidróxicolest-4-eno-6 $\alpha$-hidroperóxido (II) e $3 \beta$-hidróxicolest-4eno-6 $\beta$-hidroperóxido (III), como produtos da degradação induzida a tecidos vivos, por via fotoquímica, tanto pelo agente fototerapêutico hematoporfirina como pelo cloro-Al(III) ftalocianina tetrasulfonada, produtos característicos de reação envolvendo oxigênio singlete ${ }^{16}$.

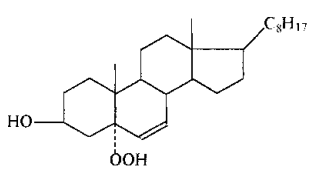

(I)

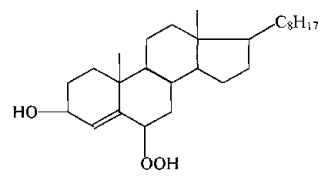

(II)

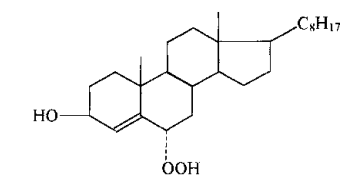

(III)
Figura 2. Representação dos produtos da reação entre colesterol e oxigênio singlete: $3 \beta$-hidróxi-5 $\alpha$-colest-6-eno-5-hidroperóxido (I), $3 \beta$ hidróxicolest-4-eno-6 $\alpha$-hidroperóxido (II) e 3 $\beta$-hidróxicolest-4-eno-6 $\beta$ hidroperóxido (III); o primeiro é preponderante, enquanto que os outros dois se formam com baixo rendimento $\left(\begin{array}{lll}1 & \text { a } & 2 \%\end{array}\right)^{16}$.

Também, o papel inibidor do íon azoteto, conhecido supressor para o oxigênio singlete ${ }^{3}$, assim como o aumento da eficiência da reação na presença de $\mathrm{D}_{2} \mathrm{O}$, tem-se verificado em sistemasmodelo $^{3,71}$. Por fim, a fosforescência do oxigênio singlete, a 1270 $\mathrm{nm}$, foi detectada em suspensões contendo células tumorais (L1210) submetidas a fotólise na presença de 5-(N-hexadecanoil) amino eosina ${ }^{17}$. Atualmente, tem-se concentrado esforços no sentido de detectar essa fosforescência in vivo ${ }^{18}$.

Ambos os mecanismos são controlados por difusão ${ }^{3,4}$. As espécies reativas geradas a partir da interação entre o estado excitado do corante e o oxigênio (oxigênio singlete e ânionradical superóxido), entre o estado excitado do corante e sítios dos substratos que estão sendo atacados $\left(S^{+}\right.$e $A^{-\cdot}$ ou $S^{-}$e $B^{+}$e ou e, dependendo das propriedades redóxi do sensitizador e do substrato), e as resultantes dos processos secundários (radicais livres e outras espécies carregadas), tendem a se difundir nas vizinhanças do tecido afetado, iniciando uma cadeia de reações bioquímicas, resultando em danos de diferentes proporções à célula tumoral, o que tende a inviabilizá-lo. Os sítios ricos em elétrons, presentes nas células-alvo, tendem a ser os mais fácilmente modificados, como por exemplo a guanina, cadeias laterais de amino-ácidos contendo estruturas aromáticas e enxôfre, ligações duplas de esteróides e lipídeos insaturados. Isso resulta em danos à parede celular, mitocôndria, e lisosomos, comprometendo a integridade celular. Nenhum efeito mutagênico sobre as células sadias tem sido reportado até o momento ${ }^{5}$, o que amplia a segurança de aplicação dessa modalidade terapêutica, permitindo ainda a repetição do tratamento no caso de recorrência ou mesmo de lesões extendidas. Os agentes fototerapêuticos podem ainda destruir um tumor indiretamente, pelo dano causado ao endotélio vascular, o que resulta em hipoxia e morte do tecido ${ }^{6}$.

Em todos os casos, o fotoprocesso inicial ocorre dentro de um espaço com diâmetro entre 10 e $50 \mathrm{~nm}^{7,8}$. Fatores químicos e biológicos tendem a propagar os efeitos a outros sítios, localizados a maiores distâncias da origem ${ }^{9}$. Isso faz com que seja necessário um estrito controle da biodistribuição do agente fototerapêutico a nível celular ou tissular, especialmente quando esses fotosensitizadores são sistêmicamente injetados, como ocorre usualmente em TFD. O emprego de sistemas distribuidores apropriados tem resultado em avanços significativos na eficácia e seletividade da TFD, já que assim, o fotosensitizador pode ser liberado em elevadas concentrações no tecido-alvo ${ }^{5,71}$.

O extraordinário desenvolvimento da pesquisa relativa a reações envolvendo oxigênio singlete, sobretudo as que envolvem sistemas biológicos ${ }^{3,6,19,54,71}$. resultou no rápido desenvolvimento dessa modalidade clínica hoje conhecida como Terapia Fotodinâmica. 


\section{HISTÓRICO}

Um tumor caracteriza-se por um crescimento anormal de tecido vivo, podendo ser benigno ou maligno (o câncer). O câncer é reconhecidamente a moléstia que mais apreensão tem provocado na história da humanidade. Os três tratamentos clássicamente adotados contra o câncer são a quimioterapia, a radioterapia e a cirurgia (remoção do tecido lesado e seus arredores), que apresentam inúmeras desvantagens, como por exemplo a desfiguração do paciente, com prejuízos à sua autoestima, inúmeros efeitos colaterais (quimioterapia e radioterapia), além de uma perspectiva de cura nem sempre eficaz. Em virtude disso, tratamentos alternativos tem-se desenvolvido ${ }^{56}$, dentre os quais se inclui a Terapia Fotodinâmica.

A Terapia Fotodinâmica visa a destruição localizada do tecido vivo anormal mediante sua necrose ou inviabilização, assim como também a desativação de vírus, destruição de bactérias e fungos $3,6,8,19-54,57,59,88,93$. O tratamento se inicia após um período de espera, após a administração ao paciente de um corante fotosensitizador (o agente fototerapêutico), usualmente por injeção intravenosa. Após esse tempo de espera, quando a concentração do corante atinge o seu máximo no tecido lesado, procede-se à exposição do tumor à radiação visível de comprimento de onda adequado para a excitação do agente fototerapêutico ${ }^{3,6}$. A radiação, geralmente fornecida por um laser, é dirigida ao local do tratamento empregando-se um feixe de fibras ópticas.

As primeiras experiências visando a aplicação do efeito fotodinâmico no tratamento de tumores em humanos foram feitas em 1903 por Tappenier e Jesionek, empregando eosina como fotosensitizador ${ }^{58}$. Embora os resultados tenham sido positivos, esse trabalho não sofreu continuidade.

Em 1924, Policard ${ }^{59}$ observou que porfirinas podiam ser encontradas em elevadas concentrações em tumores malignos. Essas porfirinas são completamente atóxicas, mas na presença de luz visível e oxigênio elas se tornam altamente tóxicas ao tecido celular.

No final dos anos 60 , Lipson ${ }^{60}$ reportou um caso de tratamento bem-sucedido de câncer de seio, empregando derivados de hematoporfirina e irradiação seletiva do tumor com luz visível.

Em 1976, Weishaupt e colaboradores ${ }^{34}$ postularam que o oxigênio singlete, gerado por sensitização, a partir da transferência de energia do agente fototerapêutico no estado triplete excitado para o oxigênio molecular no estado fundamental, era o agente citotóxico responsável pela desativação de células tumorais. Em fins dos anos 70, a partir dos trabalhos de Dougherty e colaboradores ${ }^{35}$, a TFD passou a ser reconhecida como uma alternativa para o tratamento de câncer, tendo sido empregada com sucesso no tratamento de tumores, além de outras outras condições clínicas ${ }^{8,46,61}$.

\section{AGENTES FOTOTERAPÊUTICOS}

A primeira geração de agentes fototerapêuticos, baseada em misturas de derivados porfirínicos ${ }^{19,21,29,34}$, tem-se mostrado eficiente no tratamento de tumores de diversas procedências, malignos ou não. Preferencialmente, o agente fototerapêutico tende a se concentrar no tecido lesado ${ }^{19}$. O mecanismo para essa seletividade ainda não está bem esclarecido. No entanto, sabe-se que, ao menos em parte, essa seletividade decorre da associação do agente fototerapêutico a lipoproteínas do plasma, que assim o transporta preferencialmente para as células anormais. Isso ocorre em virtude do fato dessas células possuirem um número exageradamente alto de receptores de lipoproteínas de baixa densidade, resultado de sua elevada demanda por colesterol ${ }^{40,62,63}$. Esse conhecimento tem-se mostrado bastante positivo para o desenvolvimento de procedimentos fototerapêuticos cada vez mais seletivos: o emprego de lipoproteínas, e mais recentemente, de anticorpos específicos, associados ao agente fototerapêutico, tem resultado em uma alta seletividade do tratamento, com uma cada vez maior preservação das células sadias ${ }^{62-65}$.

Um agente fototerapêutico clínicamente adequado deve possuir no seu estado triplete excitado um tempo de vida de longa duração $\left(\tau_{\mathrm{T}} \geq 500 \mathrm{~ns}\right)^{71}$, podendo reagir eficientemente tanto com moléculas vizinhas como com o oxigênio. Deve também apresentar elevada absortividade molar na região espectral compreendida entre 600 e $1000 \mathrm{~nm}$, conhecida como 'janela fototerapêutica', onde a membrana celular apresenta considerável transparência à radiação eletromagnética ${ }^{41}$. Com isso, é possível uma boa penetração da luz (maior que 2 a 3 $\mathrm{cm}$ ) em tecidos levemente pigmentados, com risco mínimo de destruição generalizada dos componentes sadios que não contém o agente fototerapêutico ${ }^{8,40}$. Essas propriedades podem ser moduladas pela inserção de características desejáveis à molécula do fotosensitizador. Por exemplo, em geral os porfirinóides coordenados a íons metálicos ou ligados a íons metálicos de camada fechada são caracterizados por possuirem um tempo de vida de triplete da ordem de alguns milisegundos, com um rendimento quântico entre 0,7 e 0,9 , e rendimento quântico de produção de oxigênio singlete superior a $0,5^{66}$. No entanto, esses valores podem sofrer decréscimo considerável em virtude da formação de agregados envolvendo o agente fototerapêutico. Isso pode ser revertido pela inclusão na estrutura de substituintes periféricos carregados que, em virtude da repulsão eletrostática, impedem ou minimizam a tendência de agregação. Como exemplo, tem-se o caso da inclusão de grupos carboxilato ou sulfonato no macrociclo desses porfirinóides, o que tem dado ótimos resultados em testes tanto in vitro como in vivo ${ }^{67}$.

A tendência de agregação também pode ser revertida pela coordenação de íons metálicos que possam sofrer hexacoordenação: a presença de substituintes axiais cria um significativo impedimento estérico, que também pode ser utilizado para proporcionar níveis predeterminados de anfifilicidade à molécula ${ }^{68}$, resultando em uma maior efetividade para o agente fototerapêutico.

Embora a intensidade e posição da banda de absorção desses compostos estejam associadas à extensão da nuvem eletrônica sobre a estrutura aromática, o máximo de absorção pode ser ajustado pelo controle da natureza do íon metálico, dos ligantes axiais, e pela posição e natureza dos substituintes periféricos.

Os derivados da hematoporfirina tem sido substituídos por uma segunda geração de agentes fototerapêuticos que possuem elevada absortividade molar na região espectral correspondente à cor vermelha, resultando assim em elevada resposta fototerapêutica, com a administração ao paciente, de doses apreciavelmente menores que as usuais ${ }^{8}$. Nessa classe estão as ftalocianinas e as clorinas ${ }^{9,69}$. As ftalocianinas, por exemplo, tem demonstrado ser um potencial agente fotosensitizador na erradicação de processos neoplásicos ${ }^{44,45}$.

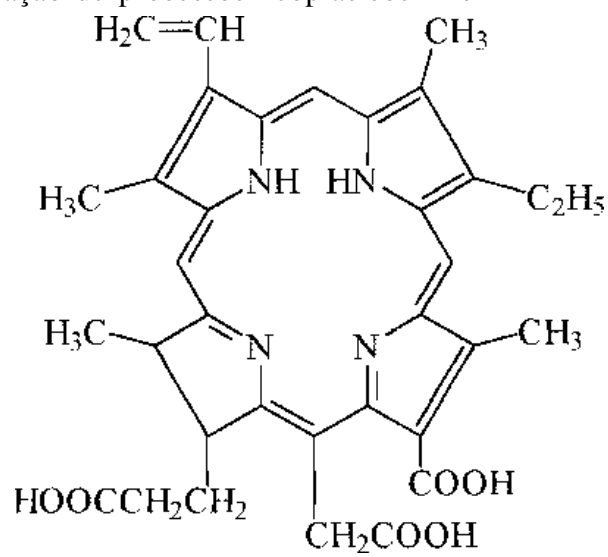

Figura 3. Estrutura típica de uma clorina (fitoclorina). 
De particular interesse é a possibilidade de uso de agentes fototerapêuticos baseados na bacterioclorina ou da família da naftalocianina, que apresentam bandas de absorção muito intensas $\left(\varepsilon=400.000\right.$ a $\left.500.000 \mathrm{M}^{-1} \mathrm{~cm}^{-1}\right)$ no infravermelho, onde a melanina apresenta uma absorvância relativamente baixa. Como consequência, a TFD pode ser extendida ao tratamento de tumores altamente pigmentados, incluindo o melanoma melanótico, que representa a neoplasia que mais cresce na Europa ${ }^{70}$.

\section{TERAPIA DE TUMORES}

O protocolo-padrão empregado em terapia de tumores, envolve a administração intravenosa do agente fototerapêutico (cerca de 2 a $5 \mathrm{mg} / \mathrm{kg}$ de massa corporal, no caso das porfirinas, e de 0,1 a $0,5 \mathrm{mg} / \mathrm{kg}$ para os agentes fototerapêuticos mais recentes $)^{8}$. Essas quantidades são ínfimas se comparadas às doses mínimas que podem induzir efeitos tóxicos em seres humanos $(300-500 \mathrm{mg} / \mathrm{kg})^{8}$. A TFD tem se mostrado, no geral, curativa para tumores cujo diâmetro não exceda cerca de $2 \mathrm{~cm}$, podendo ser empregada com propósitos paliativos no tratamento de massas neoplásicas compactas ${ }^{8,57}$. A fluência da radiação incidente deve se situar entre 100 e $200 \mathrm{mJcm}^{-2}$, de modo a evitar o sobreaquecimento dos tecidos, o que reduziria a seletividade do processo. O início do tratamento ocorre, no caso das porfirinas, de 24 a 72 h após a administração do agente fototerapêutico ${ }^{3,8,57}$.

As fontes de radiação empregadas são, em geral, lasers. A melhor fonte de radiação tem sido descrita como sendo a que por um baixo custo forneça a maior quantidade de luz possível no máximo de absorção do sensitizador, sem efeitos térmicos significativos. Raramente tem sido empregadas lâmpadas de arco de xenônio, as quais requerem o emprego de filtros adequados para a seleção do comprimento de onda de irradiação, um sistema óptico bastante eficiente a fim de dirigir a radiação ao local de irradiação com um mínimo de perdas. Com esse objetivo, feixes de fibras ópticas tem sido empregados para dirigir a radiação ao local a ser irradiado. Um eficiente sistema de dissipação do calor gerado pela lâmpada é requerido, a fim de minimizar os efeitos térmicos sobre o tecido a ser irradiado e seus arredores. Um aspecto bastante desfavorável refere-se à potência requerida para a lâmpada, para que forneça radiação com a fluência adequada no comprimento de onda requerido.

Lasers no estado sólido tipo Nd:YAG tem sido empregados mais recentemente. O problema nesse caso refere-se ao seu elevado custo. No entanto, é possível empregando-se as harmônicas de lasers Nd:YAG e alguns dispositivos ópticos, obter feixes de laser na faixa de 200 a $2000 \mathrm{~nm}$. Um exemplo desse sistema é o desenvolvido e comercializado pela Opotek, Inc. (http://www.opotek.com/Selection.htm).

Uma alternativa de custo intermediário são os lasers de diodo. Existem atualmente lasers de diodo cobrindo práticamente todo o espectro visível e infravermelho próximo, podendo assim atender boa parte dos agentes fototerapêuticos já existentes no mercado. Tais lasers são capazes de fornecer luz pulsada de considerável potência com precisão sobre o tecido a ser irradiado, graças a sistemas de distribuição baseados em feixes de fibras ópticas. Exemplos desses sistemas são as classes de lasers cirúrgicos produzidas e comercializadas pelas empresas Applied Optronics, Co. (http://optics.org/aoc/ system.html), Ceramoptec (http://ceramoptec.com) e Diomed (http://www.diomed-lasers.com/pdt.htm), desenvolvidas específicamente para uso em Terapia Fotodinâmica. Com o emprego de agentes fototerapêuticos de segunda geração, em virtude de sua elevada absortividade molar, o uso de diodos emissores de luz (LEDs) tem também se tornado viável, possibilitando uma maior redução no custo dos procedimentos.

Alguns aparatos tem sido desenvolvidos de modo a melhorar a eficiência do tratamento em casos específicos. No tratamento de câncer de bexiga, por exemplo, tem-se empregado um difusor esférico, o qual é montado na extremidade do feixe de fibras ópticas: isso melhora a distribuição de luz no interior da bexiga. Nseyo e colaboradores ${ }^{75}$ tem desenvolvido um balão que força a bexiga a assumir um formato esférico, com o difusor colocado no seu centro, o que garante uma distribuição mais uniforme da luz.

Clínicamente, a TFD já vem sendo empregada no tratamento dos seguintes casos de câncer: bexiga, pulmão, pele (primário e metastático do seio), intestino, trato digestivo superior, bexiga, dentre outros, assim como também na detecção e delineamento de lesões por fluorescência. $O$ câncer superficial de bexiga, por exemplo, é frequentemente difícil de ser detectado. No entanto, considerando-se a retenção preferencial de agentes fototerapêuticos, esses casos de câncer tem podido ser detectados pela medida da fluorescência do tecido, após a administração do agente fototerapêutico ${ }^{54}$.

Nas aplicações mais comuns da TFD se incluem:

- abertura de vias aéreas obstruídas;

- redução do tamanho de tumores cerebrais, principalmente em pacientes que não podem ser fácilmente operados;

- aplicação imediatamente após a remoção cirúrgica da lesão neoplástica.

Os agentes fototerapêuticos mais intensamente estudados são,

- Derivados da hematoporfirina (HpD), Photofrin ${ }^{\circledR}$ II (PII) e meso-tetra(hidroxifenil) clorina (mTHPC), investigados no trato otorrinolaringológico, no esôfago e árvore traqueobronquial;

- Porfirinas mediadas no ácido 5-aminolevulínico (ALA), investigadas na bexiga;

- Conjugados envolvendo anticorpo monoclonal e corante, investigados no cólon e no reto;

- Ftalocianina de Zinco (ZnPC) em lipossomos, investigada na cavidade oral;

- Derivado da benzoporfirina, investigado em oftalmologia. O agente fototerapêutico denominado Photofrin ${ }^{\circledR}$, desenvolvido pela QLT Photo-Therapeutics em fins da década de 80, foi o primeiro agente fototerapêutico a ter seu emprego em TFD autorizado por órgãos governamentais ${ }^{39,40}$. Sua natureza química exata ainda não está totalmente estabelecida, sendo considerada uma mistura de oligômeros da hematoporfirina. As ligações preponderantes entre as unidades monoméricas são ligações éter ou éster ${ }^{40,72}$.

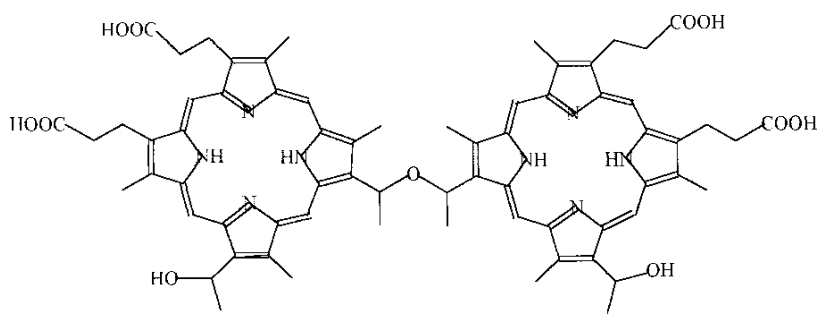

Figura 4. Representação da estrutura do agente fototerapêutico PHOTOFRIN ${ }^{\circledR}$ na forma de éter.

Photofrin ${ }^{\circledR}$ tem sido o agente fototerapêutico mais aplicado, embora não seja o mais adequado, já que entre os seus efeitos colaterais está a indução de prolongada fotosensitividade à pele. Também, absorve relativamente pouco a $630 \mathrm{~nm}$, um comprimento de onda onde a penetração da luz nos tecidos não é ótima. Além da fotosensitividade da pele, outros efeitos colaterais, muitos deles duradouros, tem sido reportados ${ }^{54}$. No tratamento do câncer de bexiga, por exemplo, os efeitos colaterais mais frequentes são crescimento da frequência e urgência urinárias e espasmos da bexiga. Tudo indica que esses problemas estão associados às altas dosagens empregadas (2-5 $\mathrm{mg} / \mathrm{kg})^{6,54}$. Muitos dos novos agentes fototerapêuticos que tem sido testados, a chamada segunda geração de fotosensitizadores, 
são químicamente puros, absorvem luz próximo ou acima de $650 \mathrm{~nm}$ com muito maior eficiência que a Photofrin ${ }^{\circledR}$, e induzem pouca ou nenhuma fotosensitividade à pele. Além disso, em função das considerávelmente baixas doses de administração os efeitos colaterais tendem a ser muito pouco ou nada pronunciados - para a meso-tetra(hidroxifenil) clorina $\left(\lambda_{\text {máx }}=652 \mathrm{~nm}\right)$, por exemplo, cuja dose de admnistração recomendada é $0,3 \mathrm{mg} / \mathrm{kg}$, um menor período de espera para iniciar o tratamento é requerido, além da ocorrência de rápida eliminação do agente fototerapêutico após o tratamento ${ }^{74}$.

Uma outra classe de fotosensitizadores são os endógenos, baseados na administração por via oral ou mesmo por uso tópico do ácido $\delta$-aminolevulínico (ALA = ácido 5-amino-4oxopentanóico $)^{54}$. Esse ácido é o precursor metabólico da protoporfirina IX (PpIX) na rota biosintética para a heme ${ }^{73}$. Em contraste com o ALA, PpIX é fotodinâmicamente ativo.

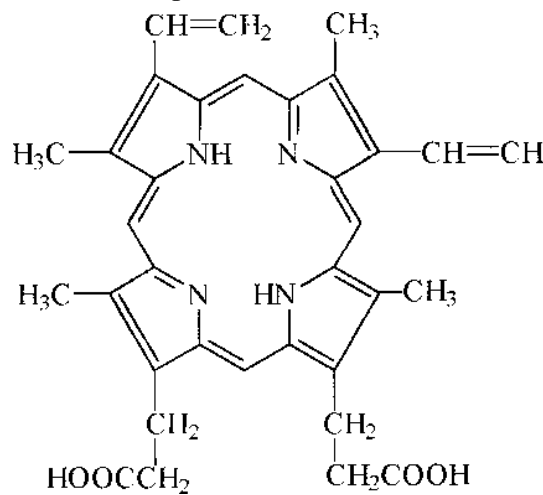

Figura 5. Representação da estrutura da protoporfirina IX (PpIX).

A ausência de efeitos colaterais associados ao agente fototerapêutico em muitos casos, com exceção de uma fotosensitividade geral da pele, permite a repetição do tratamento por várias vezes, o que pode em particular ser útil no caso de lesões múltiplas ou neoplasias metastáticas.

Desenvolvimentos mais recentes tem possibilitado a introdução de alguma flexibilidade nos protocolos usuais de TFD, incluindo-se aí a aplicação tópica do agente fototerapêutico ${ }^{54}$. Estudos farmacocinéticos com uma série de porficenos tem mostrado, por exemplo, que a tetrametoxilação induz um significativo aumento na taxa de eliminação do agente fototerapêutico, observando-se sua completa eliminação uma hora após a admnistração ${ }^{65}$. Isso traz a possibilidade de que o tratamento fototerápico possa ser iniciado em um curto espaço de tempo após a administração sistêmica do fotosensitizador, eliminandose também os problemas de fotosensibilidade da pele, associados à permanencia do agente fototerapêutico no organismo.

A experiência tem mostrado, portanto, que ao menos quatro parâmetros devem ser levados em consideração no desenvolvimento de novos agentes fototerapêuticos:

- toxidez;

- eficiência na geração de oxigênio singlete;

- capacidade de penetração na membrana celular;

- velocidade de eliminação pelo organismo após o tratamento.

A TFD mostra-se bastante atraente no tratamento de casos de câncer de pulmão, considerando-se que requer técnicas invasivas mínimas, podendo o tratamento ser repetido várias vezes ${ }^{54,76}$.

Em casos iniciais, o índice de sucesso dos tratamentos empregando TFD tem-se mostrado elevado ${ }^{40,77}$. Em casos avançados, o tratamento mostra-se mais dificultado em função de complicações associadas ao estado geral do paciente, como por exemplo no caso de pacientes portadores de grandes tumores obstrutivos. No geral, esses pacientes já receberam tratamento prévio por radioterapia ou por laser (ablação empregando laser $\mathrm{Nd}$ :YAG), os quais tendem a comprometer o tecido normal nas proximidades da lesão ${ }^{54}$. Outra complicação comum encontrada refere-se ao tratamento de pacientes que se encontram com a capacidade respiratória bastante comprometida: o tratamento com TFD pode causar edema e algumas vezes obstrução das vias respiratórias causada pelo tumor necrótico. Há portanto uma clara necessidade de remoção do tecido necrosado, dentro de, no máximo, dois dias após o tratamento.

Aplicações clínicas da TFD no tratamento de câncer pulmonar vem sendo feitas no Japão desde $1980^{79,80}$. TFD tem sido aplicada clínicamente tanto em casos iniciais como nos avançados (nesses casos, em combinação com cirurgia). Este tratamento pode preservar a função pulmonar, é bem tolerado e de baixo custo, quando comparado com outros tratamentos. Embora em casos avançados desse tipo de câncer, a TFD não resulte em tratamento curativo, tem-se reportado que a aplicação de TFD como um tratamento paliativo pode melhorar a qualidade e expectativa de vida do paciente ${ }^{79,81}$

O primeiro caso no mundo de tratamento de câncer pulmonar em estágio inicial, por TFD, ocorreu em 1980, aplicado a um homem de 74 anos, com tumor localizado no brônquio direito (carcinoma escamoso de 2 a $3 \mathrm{~mm}$ ), obtendo-se completa remissão do tumor. Após sua morte 4 anos depois, de pneumonia, a autopsia mostrou que não havia nenhum sinal do tumor que havia sido eliminado por $\mathrm{TFD}^{80}$.

O emprego de TFD no tratamento de lesões avançadas, tende a aumentar a operabilidade do paciente, assim como também reduzir o volume do tumor que necessita ser removido. TFD tem, por exemplo, sido bem-sucedida na desobstrução de brônquios estenóticos ou obstruídos, com um índice de sucesso de $74,7 \%{ }^{81}$.

O câncer de bexiga responde por aproximadamente $3 \%$ dos casos registrados de câncer. De sua totalidade, cerca de $2 \%$ mostram-se resistentes ao tratamento convencional e possuem elevado risco de progressão. A TFD é, no caso do câncer de bexiga, mais indicada para o tratamento dos casos superficiais. O propósito da TFD no tratamento do câncer de bexiga é duplo: erradicação dos focos visíveis e invisíveis, e prevenção de recorrência após procedimento cirúrgico para remoção do tumor ${ }^{54}$

Câncer de pele é, de longe, o mais comum de todos os casos de câncer. Só nos EUA, estima-se que entre 900.000 e 1.200.000 novos casos de câncer de pele (não-melanoma) são diagnosticados por ano ${ }^{54}$. Nos últimos 10 anos, a TFD com a aplicação sistêmica de Photofrin ${ }^{\circledR}$ tem sido empregada na terapia de diversos tipos de tumores malignos, tanto cutâneos como subcutâneos, incluindo-se carcinoma de células basais ${ }^{82}$, doença de Bowen ${ }^{83}$, carcinoma de células escamosas ${ }^{84}$, carcinoma de seio, recorrente e metastático ${ }^{85}$ e sarcoma de Kaposi ${ }^{86}$. Em alguns casos, a TFD também tem sido empregada como paliativo no caso de melanoma metastático ${ }^{85}$. No caso de lesões primárias envolvendo a pele, tem-se reportado um alto índice de casos bem-sucedidos $(>80 \%)$, combinadas a excelentes resultados cosméticos. No caso da pele já é possível a aplicação tópica do agente fototerapêutico, com resultados bastante positivos no caso de malignâncias primárias ${ }^{87,88}$, assim como no caso de tumores superficiais de pele tipo não-melanoma, onde se tem feito a aplicação tópica do ácido d-aminolevulínico ${ }^{23}$.

\section{TRATAMENTOS JÁ APROVADOS}

O emprego de procedimentos envolvendo Terapia Fotodinâmica tem sido muito difundido nos países do primeiro mun$\mathrm{do}^{23,29,39,40}$. Em 1994, o governo Japonês autorizou o emprego da droga denominada Photofrin ${ }^{\circledR}$ na terapia de câncer de pulmão. Em 1995, o governo Norte-Americano autorizou o emprego dessa mesma droga na terapia de câncer do esôfago ${ }^{39}$. Em 1996, foi a vez do governo Francês. Nesses países, em virtude dos estímulos concedidos à pesquisa neste campo, diversos procedimentos clínicos tem sido estabelecidos, sendo que alguns deles já vem tendo o seu emprego autorizado: 
- Nos Estados Unidos: tratamento paliativo para pacientes com tumores totalmente obstrutivos e cânceres de esôfago parcialmente obstrutivos onde a terapia a laser (thermal laser therapy) seja considerada imprópria; também, certos tipos específicos de câncer de pulmão (submetido à FDA em fevereiro de 1997);

- Na França e Holanda: tratamento de câncer de pulmão e esôfago;

- No Canadá: câncer de esôfago, câncer recorrente de bexiga (recurrent papillary bladder cancer), redução de tumores obstrutivos e tratamento paliativo de disfagia em pacientes com câncer de esôfago completamente ou parcialmente obstrutivos;

- No Japão: câncer de pulmão em estágio inicial, cânceres gástricos superficiais e em estágio inicial, câncer cervical em estágio inicial, displasia cervical;

- Na Holanda: câncer de pulmão obstrutivo e em estágio inicial, câncer gástrico e cervical (incluindo displasia cervical), e cânceres superficiais gástrico e de esôfago.

\section{OUTRAS APLICAÇÕES E PERSPECTIVAS}

Embora a TFD tenha sido originalmente desenvolvida visando a terapia do câncer em suas diversas formas, tem ficado claro seu grande potencial no que concerne a outras moléstias. Nesse rol incluem-se a psoríase ${ }^{40,89}$, onde se tem atingido resultados bastante promissores, degeneração macular da retina, condições autoimunes, arteriosclerose e restenose ${ }^{40}$, remoção de verrugas na laringe ${ }^{90}$, tratamento de micoses fungóides ${ }^{88}$, e destruição de infestações bacterianas resistentes a tratamentos tradicionais à base de antibióticos ${ }^{93}$.

Estudos relativos à descontaminação do sangue tem sido reportados: tem-se conseguido relativo sucesso na desativação do vírus da herpes (Herpes simplex -1, herpes simplex - 2, varicela zoster), pelo emprego de diferentes derivados da ftalocianina. A análise ultraestrutural dos vírus da herpes, submetidos à ação de um agente fototerapêutico, demonstra a ocorrência de dano ao envelope viral, o que inviabiliza sua adsorção ou penetração nas células sadias. No entanto, adenovirus sem o envelope proteico tem-se mostrado resistentes a todos os agentes fototerapêuticos testados. Também, os virus que já se encontram no interior de células tem se mostrado mais resistentes ao tratamento que os virus livres. Por outro lado, os danos às células sanguíneas são mínimos ${ }^{31,46,91,92}$.

\section{CONCLUSÃO}

A Terapia Fotodinâmica tem-se mostrado uma modalidade clínica promissora para o tratamento do câncer, que oferece a possibilidade de remissão ou mesmo ação paliativa em certos casos de câncer. Também, tem-se mostrado aplicável em um número considerável de outras moléstias, assim como na descontaminação de sangue. Em alguns casos, quando as moléstias se tornam refratárias às terapias existentes, a TFD tem-se mostrado uma alternativa viável de tratamento. A tendência de pesquisas futuras em TFD tem-se voltado para o desenvolvimento de novos sensitizadores com características melhoradas, como por exemplo maior seletividade frente às células e ou tecidos-alvo, e maior absortividade molar no seu máximo de absorção, de modo a permitir uma maior efetividade do tratamento.

Pode-se considerar que o extraordinário desenvolvimento da TFD decorre do seu conceito básico, relativamente simples: a combinação de uma droga sensitizadora, luz de comprimento de onda adequado, e oxigênio, e à elevada interdisciplinaridade que se tem atingido na pesquisa envolvendo essa modalidade terapêutica. Esse campo de pesquisa tem, por motivos óbvios, experimentado um acentuado desenvolvimento, tanto na pesquisa médica como no desenvolvimento de novos agentes fototerapêuticos cada vez mais eficazes e seletivos. No entanto, infelizmente, muito pouco tem sido feito no nosso país no sentido de estimular a pesquisa e o desenvolvimento nessa modalidade terapêutica, e consequentemente sua aplicação, embora deva-se reconhecer que este tema de pesquisa possui grande interesse estratégico.

Alguns importantes trabalhos de revisão e divulgação sobre o tema tem sido publicados em língua inglesa $a^{6,8,9,40,50,54,7179,94,95}$.

\section{AGRADECIMENTOS}

Ao CNPq e à FAPEMIG, e às valiosas sugestões dos colegas Prof. Dr. Carlos Alberto de Oliveira (IQ/UFU), e Divinomar Severino (Doutorando - IQ/UFRJ). Ao Prof. Dr. David E. Nicodem (Laboratório de Fotoquímica - DQO, IQ/UFRJ), pela gentil acolhida quando da minha permanência em seu laboratório.

\section{REFÊRENCIA}

1. Zollinger, H.; Color Chemistry - Syntheses, Properties and Applications of Organic Dyes and Pigments, VCG Publishers. Weinheim, 1991, $2^{\text {nd }}$ Edition

2. Raab, O.; Z. Biol. 1900, 39, 524.

3. a) Frimer, A. A. (Ed.); Singlet Oxygen, CRC Press, Califórnia, 1989. b) Wilkinson, F.; Phillip Helman, W.; Ross, A. B.; J. Phys. Chem. Ref. Data 1995, 24, 663. c) Ogilby, P. R.; Foote, C. S.; J. Am. Chem. Soc. 1983, 105, 3423.

4. Zhang, X.; Rodgers, M. A. J.; J. Phys. Chem. 1995, 99, 12797.

5. Goldsten, J. L.; Brown, M. S.; Anderson, R. G.; Russell, D. W.; Schneider, W. J.; Rev. Cell. Biol. 1985, $1,1$.

6. Nseyo, U. O.; Urol. Clin. North Am. 1992 19, 591.

7. Moan, J.; J. Photochem. Photobiol. 1990, B6, 343.

8. Jori, G.; EPA Newsletter 1997, 60, 12.

9. Jori, G.; Schindl, L.; Schindl, A.; Polo, L.; J. Photochem. Photobiol. 1996, A102, 101.

10. Gollnick, K.; Adv. Photochem. 1968, 6, 1.

11. Kavarnos, G. J.; Turro, N. J.; Chem. Rev. 1986, 86, 401.

12. Gilbert, A.; Baggott, J.; Essentials of Molecular Photochemistry, Blackwell Scientific Publications, Oxford, 1991.

13. van Lier, J. E.; Brasseur, N.; Gantchev, T. G.; Abstracts do Singlet Molecular Oxygen - Chemical, Biological and Medical aspects, Caraguatatuba, São Paulo, 1998. Pag. 25.

14. Korytowski, W.; Bachowski, G. J.; Girotti, A.W.; Photochem. Photobiol. 1992, 56, 1.

15. Geiger, P. G.; Korytowski, W.; Girotti, A. W.; Photochem. Photobiol. 1995, 62, 580.

16. Kulig, M. J., Smith, L. L.; J. Org. Chem. 1973, 38, 3639.

17. Baker, A.; Kanofsky, J. R.; Photochem. Photobiol. 1992, 57, 720 .

18. Gorman, A. A.; Rodgers, M. A. J.; J. Photochem. Photobiol. 1992, B14, 159

19. Hamblin, M. R.; Newman, E. L.; J. Photochem. Photobiol. 1994, B23, 3 .

20. Schiwon, K.; Brauer, H. -D.; Gerlach, B.; Muller, C. M.; Montforts, F. -P.; J. Photochem. Photobiol. 1994, B23, 239.

21. Jones, L. R.; Grossweiner, L. I.; J. Photochem. Photobiol. 1994, B26, 249.

22. Daya-Grosjean, L.; Dumaz, N.; Sarasin, A.; J. Photochem. Photobiol. 1995, B28, 115.

23. Calzavara-Pinton, P. G.; J. Photochem. Photobiol. 1995, B29, 53.

24. Giacomoni, P. U.; J. Photochem. Photobiol. 1995, B29, 87.

25. Ricchelli, F.; J. Photochem. Photobiol. 1995, B29, 109.

26. Giuffrida, S.; De Guidi, G.; Chillemi, R.; Costanzo, L. L.;Condorelli, G.; J. Photochem. Photobiol. 1995, B29, 125.

27. Cubeddu, R.; Canti, G.; Taroni, P.; Valentini, G.; J. Photochem. Photobiol. 1995 B29, 171.

28. Lutgerink, J. T.; van den Akker, E.; Smeets, I.; Pachen, D.; van Dijk, P.; Aubry, J. -M.; Joenje, H.; Lafleur, M. V. M.; Retèl, J.; Mutation Res. 1992, 275, 377. 
29. Charlesworth, P.; Truscott, T. G.; Kessel, D.; Medforth,C. J.; Smith, K. M.; J. Chem. Soc. Faraday Trans. 1994, 90, 1073.

30. Diwu, Z.; Lown, J. W.; J. Photochem. Photobiol. 1992, A69, 191.

31. Ben Hur, E.; Hoeben, R. C.; Van Ormondt, H.; Dubbelman, T. M. A. R.; Van Steveninck, J.; J. Photochem. Photobiol. 1992, B13, 145.

32. Krishnamurty, H. G.; Simpson, F. J.; J. Biol. Chem. 1970, $245,1467$.

33. Stark, A. -A. et allii; Carcinogenesis, 1990 11, 529.

34. Weishaupt, K. R.; Gomer, C. J.; Dougherty, T. J.; Cancer Res. 1976, 36, 2326.

35. Dougherty, T. J.; Kaufman, J. E.; Goldfarb, A.; Weishaupt, K. R.; Boyle, D.; Mittleman, A.; Cancer Res. 1978, 38, 2628.

36. Lilius,E. -M.; Marnila, P.; Experientia 1992, 48, 1082.

37. Tilbury, R. N.; Experientia 1992, 48, 1030.

38. Formane, H. J.; Thomas, M. J.; Ann. Rev. Physiol. 1986, $48,669$.

39. Folha de São Paulo, 29/12/1995.

40. Levy, J. G.; Trends in Biotechnol. 1995, 13, 14.

41. Star, W. M.; Marijnissen, J. P. A.; van Gemert, M. J. C.; J.Photochem.Photobiol. 1987, B1, 149.

42. Charlesworth, P.; Truscott, T. G.; Brooks, R. C.; Wilson, B. C.; J.Photochem.Photobiol. 1994, B26, 277.

43. Bishop, S. M.; Beeby, A.; Parker, A. W.; Foley, M. S. C.; Phillips, D.; J. Photochem. Photobiol. 1995, A90, 39.

44. Spikes, J. D.; Photochem. Photobiol. 1986, 43, 691.

45. Rosenthal, I.; Photochem. Photobiol. 1991, 53, 859.

46. Smetana, Z.; Mendelson, E.; Manor, J.; van Lier, J. E.; Ben Hur, E.; Salzberg, S.; Malik, Z.; J. Photochem. Photobiol. 1994, B22, 37.

47. Reszka, K. J.; Bilski, P.; Chignell, C. F.; Hartley, J. A.; Khan, N.; Souhami, R. L.; Mendonca, A. J.; Lown, J. W.; J. Photochem. Photobiol. 1992, B15, 317.

48. Lightdale, C. J.; Heier, S. K.; Marcon, N. E.; McCaughan Jr., J. S.; Gerdes, H.; Overholt, B. F.; Sivak Jr., M. V.; Stiegmann, G. V.; Nava, H. R.; Gastroint. Endos. 1995, $42,507$.

49. Furuse, K.; Fukuoka, M.; Kato, H.; Horai, T.; Kubota, K.; Kodama, N.; Kusunoki, Y.; Takifuji, N.; Okunaka, T.; Konaka, C.; Wada, H.; Hayata, Y.; J. Clin. Oncol. 1993, 11, 1852

50. Kato, H., Horai, T.; Furuse, K.; Fukuoka, M.; Suzuki, S.; Hiki, Y.; Ito, Y.; Mimura, S.; Tenjin, Y.; Hisazumi, H.; Hayata, Y.; Jpn. J. Cancer Res. 1993, 84, 1209.

51. Braichotte, D. R.; Wagnières, G. A.; Bays, R.; Monnier, P.; van den Bergh, H. E.; Cancer 1995, 75, 2768.

52. Reddi E.; J. Photochem. Photobiol. 1997, B37, 189.

53. Fernandez, J. M.; Bilgin, M. D.; Grossweiner, L. I.; J. Photochem. Photobiol., 1997 B37, 131.

54. Schuitmaker, J. J.; Baas, P.; van Leengoed, H. L. L. M.; van der Meulen, F. W.; Star, W. M.; van Zandwijk, N.; J. Photochem. Photobiol. 1996, B34, 3.

55. Miller, D. L.; Weinstock, M. A.; J. Amer. Acad. Dermatol. 1994, 30, 774

56. RevistaTime, maio/1998, pp. 12 - 25.

57. Perria, C.; In Photodiagnostic and Phototherapeutic Techniques in Medicine; G. Jori e C. Perria, Eds., Documento Editoriale, Milano, 1995.

58. Tappenier, H.; Jesionek, A.; Muench. Med. Wochschr. 1903, 1, 2042.

59. Policard, A.; C. R. Soc. Biol. Paris 1924, 91, 1423.

60. Lipson, R. L.; Proc. $9^{\text {th }}$ International Cancer Congress, Tokio, Japan, 1966, p. 393

61. Richter, A. M.; Jain, A. K.; Obochi, M.; Meadows, H.; Canaan, H.; Levy, J. G.; Photochem. Photobiol. 1994, $59,350$.

62. Reddi, E.; J. Photochem. Photobiol. 1997, B37, 189.

63. Jori, G.; Beltramini, M.; Reddi, E.; Salvato, B.; Pagnan,
A.; Ziron, L.; Tomio, L.; Tsanov, T.; Cancer Lett. 1984 , $24,291$.

64. Oseroff, A. R.; Ara, G.; Ohuoha, D.; Aprille, J.; Bommer, J. C.; Yarmush, M. L.; Foley, J.; Cincotta, L.; Photochem. Photobiol. 1987, 46, 83.

65. Hoebke, M. J.; J. Photochem. Photobiol. 1995, B28,189.

66. Reddi, E.; Jori, G.; Rev. Chem. Interm. 1988, 10, 241.

67. Bock, G.; Harnett, S.; Photosensitizing Compounds: their Chemistry, Biology and Clinical use, Wiley, Chichester, 1989.

68. Chakrabarty, A. N.; Molnár, J.; Dastidar, S. G.; Motohashi, N. (EDS.); Non Antibiotics, Niscon, New Delhi, India, 1998, Cap. 19.

69. Zhou, C.; J. Photochem. Photobiol. 1989, B3, 299.

70. Biolo, R.; Jori, G.; Pratesi, R.; Rihter, B.; Kenney, M. E.; Rodgers, M. A. J.; Photochem. Photobiol. 1994, 59, 362.

71. Ochsner, M.; J. Photochem. Photobiol. 1997, B39, 1.

72. Fisher, A. M. R.; Murphee, A. L.; Gomer, C. J.; Lasers Surg. Med. 1995, 17, 2.

73. Uchibayashi, T.; Koshida, K.; Kunimi, K.; Hisazumi, H.; Br. J. Cancer 1995, 71, 625 .

74. Savary, J. F.; Fontolliet, Ch., Braichotte, D., Monnier, Ph., Van den Bergh, H.; Proc. $5^{\text {th }}$ Int. Photodynamic Assoc. Biennial Meeting, 1994, Flórida, USA. p.37.

75. Nseyo, U. O.; Lundahl, S. L.; Merrill, D. C.; Urology 1990, 36, 398

76. Mitchell, J. B. et al. In Phototherapy of Cancer; Morstyn, G., Kaye, A. H., Eds.; Harwood Academic Publ.; Chur, 1990, pp.1-22.

77. Furuse, K.; Fukuoka, M.; Kato, H.; J. Clin. Oncol. 1993, $11,1852$.

78. Sutedja, G.; Baas, P.; Stewart, F. A.; van Zandwijk, N.; Eur. J. Cancer 1992, 28a, 1370.

79. Kato, H.; J. Photochem. Photobiol. 1998, B42, 96.

80. Hayata, Y.; Kato, H.; Konada, C.; Ono, J.; Takizawa, N.; CHEST 1982, 81, 269.

81. Kato, H.; Ann. Thorac. Cardiovasc. Surg. 1995, 1, 261.

82. Kennedy, J. C.; Pottier, R. H.; J. Photochem. Photobiol. 1991, B14, 275.

83. Jones, C.; Cooper, M.; Mang, T. S.; Wilson, B. D.; Stoll, H. L.; J. Am. Acad. Dermatol. 1992, 27, 979.

84. Wilson, B. D.; Mang, T. S.; Cooper, M.; Stoll, H.; Facial Plast. Surg. 1989, 6, 185.

85. McCaughan Jr., J. S.; Guy, J. T.; Hicks, W.; Laufman, L.; Nims, T. A.; Walker, J.; Arch. Surgery 1989, 124, 211.

86. Schweitzer, V. G.; Visscher, D.; Otolaryngol. Head Neck Surg., 1990 102, 639.

87. Svanberg, K.; Anderson, T.; Killander, D.; Wang, I.; Stenram, U.; Andersson-Engels, S.; Berg, R.; Johansson, J.; Svanberg, S.; Br. J. Dermatol. 1994, 130, 743.

88. Wolf, P.; Fink-Puches, R.; Cerroni, L.; Kerl, H.; J. Am. Acad. Derm. 1994, 31, 678.

89. Weinstein, G. D.; McCullough, J. L.; Nelson, J. S.; Berns, M. W.; J. Invers. Dermatol. 1991, 96, 573.

90. Abramson, A. L.; Shikowitz, M. J.; Mullooly, V. M.; Steinberg, B. M.; Amella, C. A.; Rothstein, H. R.; Arch. Otolaryngol. Head Neck Surg. 1992, 118, 25.

91. Ben Hur, E.; Malik, Z.; Dubbelman, T. M. A. R.; Margaron, P.; Ali, H.; van Lier, J. E.; Photochem. Photobiol. 1993, 58, 351.

92. Ben Hur, E.; Horowitz, B.; Photochem. Photobiol. 1995, $62,383$.

93. van der Meulen, F. W.; Ibrahim, K.; Sterenborg, H. J. C. M.; Alphen, L. V.; Maikoe, A.; Dankert, J.; J. Photochem. Photobiol. 1997, B40, 204.

94. Dougherty, T. J.; Gomer, C. J.; Henderson, B. W.; Jori, G.; Kessel, D.; Korbelik, M.; Moan, J.; Peng, Q.; J. Natl. Cancer Inst. 1998, 90, 889.

95. Sternberg, E. D.; Dolphin, D.; Brückner, C.; Tetrahedron 1998, 54,4151 . 